\title{
Um estudo qualitativo sobre inclusão escolar
}

\section{A qualitative study on inclusion in schools}

\author{
Maria da Graça Tavares Monteiro* \\ Maria de Lourdes Sá Earp**
}

Resumo: A inclusão escolar de crianças com deficiência é uma realidade na atualidade do campo educacional do país. Como em toda mudança de paradigma, esse movimento tem encontrado dificuldades em ser implementado (MANTOAN, 2006). Para Marquezan (2009), nossa legislação traz um discurso redutor do sujeito deficiente e Diniz (2007) esclarece que uma compreensão simplificada da deficiência, como expressão de uma lesão, limita a participação social do indivíduo. Este trabalho é de cunho etnográfico, em que privilegiamos observações e entrevistas aprofundadas. Tem como objetivo descrever, conhecer e analisar modos de agir de professores cujas salas de aula têm alunos considerados "incluídos” em duas escolas, uma pública e outra privada, na cidade de Petrópolis, escolhidas por serem "escolas inclusivas”. Como resultado da pesquisa, observamos que práticas integracionistas e segregacionistas convivem com práticas inclusivistas e se misturam no cotidiano das escolas. Buscamos nesta pesquisa ampliar as formas de pensar sobre as práticas pedagógicas a partir de uma mudança de concepção sobre a deficiência e no reconhecimento da diferença como um elemento favorecedor da aprendizagem.

Palavras-chave: Práticas pedagógicas. Etnografia. Inclusão escolar. Sala de aula.

Abstract: The inclusion of children with disabilities in schools is a reality in the educational field in the country nowadays. As in any paradigm shift, this movement has encountered difficulties in being implemented (MANTOAN, 2006). In the opinion of Marquezan (2009), our legislation provides a reductive discourse regarding people with disabilities, and Diniz (2007) makes it clear that a simplified understanding of disability as an expression of an injury, limits the individual's social participation. This present work is from an ethnographic perspective and we focus on in-depth interviews and observations. It aims to describe, understand and to analyze the methods of teachers whose classrooms have students considered "included" in two schools, one public and one private, in the city of Petrópolis - chosen because they are "inclusive schools". As a result of this research, we found that integrationist and segregationist practices coexist with inclusionist practices and mingle in the daily life of schools. In this research we seek to expand ways of thinking about teaching practice from a change in the conception of disability and the recognition of difference as an element to facilitate learning.

Keywords: Pedagogical practices. Ethnography. Inclusion in schools. Classroom.

\section{Introdução}

A inclusão escolar de pessoas deficientes é fruto de um movimento maior, o de inclusão social. As práticas de inclusão estão se tornando uma realidade em nosso país e, como muitos anunciam, "um caminho sem volta” (MANTOAN, 2006, p. 61). Como

\footnotetext{
*Mestre em Educação (PUC-Rio) e doutora em Antropologia (UFRJ/IFCS). Pesquisadora da Fundação Cesgranrio. E-mail: <malusaearp@gmail.com>.

** Mestre em Educação. Professora da Universidade Católica de Petrópolis. E-mail: <mgtmonteiro@globo.com>.
} 
ocorre em toda mudança de paradigma, esse movimento vem cercado de inseguranças, incertezas e de dificuldades para ser implementado.

Este texto está organizado de modo a contemplar, num primeiro momento, um panorama sobre a deficiência, descrevendo como se desenvolveu historicamente a educação para pessoas deficientes, permeada pelos paradigmas que a influenciaram, também discorrendo sobre os pressupostos legais que regem esta modalidade de ensino. Num segundo momento, apresentamos a metodologia utilizada, que privilegiou a abordagem qualitativa de pesquisa. Em seguida, discutiremos a questão da inclusão escolar por meio de categorias de análise, elaboradas no sentido de dar conta do objetivo da pesquisa: descrever para conhecer o processo de inclusão escolar.

\section{Deficiência: história e legislação}

A história da escolarização de pessoas com deficiência começou no século XVI, em que médicos e pedagogos, por acreditarem nas possibilidades daqueles considerados até então "ineducáveis", iniciaram um cuidado custodial destes indivíduos. Essa conduta, segundo Mendes (2006), protegia a sociedade dos “anormais”. No século XIX surgem as classes especiais nas escolas regulares, para onde eram encaminhados os indivíduos que as escolas não conseguiam alfabetizar. As oportunidades educacionais foram ampliadas para a população em geral e alcançaram pessoas com deficiência, mas só irão proliferar como modalidade alternativa às instituições residenciais depois das duas grandes guerras. Crianças e jovens com deficiências, que até a década de 1950 ainda eram mantidos segregados, foram beneficiados com a indústria da reabilitação, desenvolvida após a II Guerra, que buscava atender os mutilados pós-guerra. Segundo Mendes (2006, p. 387),

a segregação era baseada na crença de que eles, crianças e jovens com deficiência, seriam mais bem atendidos em suas necessidades educacionais se ensinados em ambientes separados.

Porém, a complexidade da análise sobre a deficiência contribuiu para a estigmatização daqueles que apresentavam "uma característica diferente da que havíamos previsto" (GOFFMAN, 1975, p. 14).

Segundo o Dicionário Houaiss de Língua Portuguesa (2001), a palavra deficiência inicialmente é definida de um ponto de vista médico, pois significa "insuficiência ou ausência de funcionamento de um órgão”; tem como sinonímia "imperfeição" e também significa "perda de valor, falha, fraqueza". Dessa forma, associados a uma ausência de valores, à fraqueza e à insuficiência, e identificados com a diferença e a desigualdade, os deficientes, desde a Antiguidade, eram culpabilizados por não possuírem atributos aceitos por determinados grupos sociais.

Com o avanço da ciência, alguns tabus foram derrubados, pois foram conhecidas várias causas para doenças que levavam às limitações. Por outro lado, o mesmo desenvolvimento permitiu que muitas pessoas sobrevivessem a situações limites. Há anos a deficiência é compreendida como própria do indivíduo e a ciência se empenhava em caracterizar e categorizar a partir de um modelo médico de deficiência, ou seja, pela patologia. Diniz (2007, p. 68) explica que segundo esse modelo a pessoa deficiente deve estar sob cuidados biomédicos e a deficiência é considerada uma consequência inevitável da lesão em um corpo:

Para o modelo biomédico da deficiência, um corpo com impedimentos deve ser 
objeto de intervenção dos saberes biomédicos. Os impedimentos são classificados pela ordem médica, que descreve as lesões e as doenças como desvantagens naturais e indesejadas.

Aquela população do pós-guerra, composta por homens jovens saudáveis, mas com lesões físicas, precursores do movimento social da deficiência, começou a questionar as limitações impostas por uma sociedade que impõe barreiras e provoca experiências de desigualdade (DINIZ, 2007). Dessa forma, as críticas às práticas segregacionistas favoreceram a modificação para um paradigma integracionista e a ênfase se deslocou dos fatores orgânicos ou individuais para os fatores sociais e ambientais, ocorrendo um processo de transição do modelo médico para o modelo social da deficiência, ainda segundo Diniz.

As práticas de integração que se desenvolveram inicialmente nas escolas procuravam aproximar cada vez mais as pessoas com deficiência dos padrões da escola comum e as crianças, então, agrupadas em classes especiais, frequentavam as escolas regulares. Anjos (2009, p. 117) esclarece que "numa visão integracionista, a presença destes alunos não modifica a lógica de funcionamento da escola”.

Numa outra direção, os movimentos sociais dos anos 1960 fizeram emergir as primeiras associações formadas por deficientes e gerenciadas por deficientes, diferentemente das sociedades antigas, que eram para deficientes. A originalidade dessas associações é que elas não eram somente de e para deficientes, já que despontaram também como um movimento de resistência política e intelectual ao modelo médico de compreensão da deficiência. Para o modelo social, que surgiu a partir dessas ações, diferentemente das abordagens biomédicas, a deficiência passou a representar um conceito político: a expressão da desvantagem social sofrida pelas pessoas com diferentes lesões (DINIZ, 2007).

Esse movimento contribuiu com o paradigma inclusivista dos anos 1990, que, segundo Anjos (2009), em vez de se tentar fornecer ao aluno condições de adaptar-se à escola, deve-se procurar construir uma escola que atenda às pessoas concretas que fazem parte dela. A difusão dessas ideias ampliou-se:

[...] a atuação conjunta de pessoas que vivem diferentemente o acesso ao conhecimento deveria contagiar o coletivo, abrindo novas experiências curriculares, flexibilizando a grade de disciplinas e a estrutura de séries. Enfim, criando novas lógicas no interior da escola e nas relações educativas como um todo. (ANJOS, 2009, p. 117)

Porém, Albrecht (apud DINIZ 2007, p. 71) argumenta que "há quem diga que a deficiência é um enigma que se experimenta, mas pouco se compreende” e os aspectos que envolvem a discussão sobre a deficiência possuem grande variabilidade de olhares. De acordo com Diniz (2007), isso ocorre principalmente como resultado do processo histórico de afastamento social que os deficientes viviam, levando a um não conhecimento sobre a diversidade de estilos de vida dos deficientes, com dificuldade inclusive de se legislar sobre o assunto.

Sendo assim, a inclusão escolar de crianças deficientes tem encontrado barreiras, seja por meio de um discurso redutor sobre o sujeito deficiente encontrado na legislação brasileira (MARQUEZAN, 2009), seja pela compreensão reduzida de que a deficiência é uma expressão de uma lesão que limita a participação social de um indivíduo, explica Diniz (2007).

No Brasil, a tarefa de incluir todos os alunos está na legislação educacional. Encontramos no Art. 208 da Constituição 
Federal e no Estatuto da Criança e do Adolescente (ECA) Art. 54 a garantia do direito à educação. Na Lei de Diretrizes e Bases da Educação, n 9.394/96, há a extensão desse direito no Capítulo V, "Da Educação Especial”, Artigo 58, "preferencialmente na rede regular de ensino, para educandos portadores de necessidades especiais”.

Além dessas leis iniciais, o Brasil se tornou signatário de documentos gerados em muitos congressos, tais como a Declaração de Jomtien, na Tailândia, nos anos 1990 Conferência Mundial sobre Educação para Todos; a Conferência Mundial sobre Necessidades Educacionais Especiais em Salamanca, Espanha, em 1994; e, em 1999, a Convenção Interamericana para a eliminação de todas as formas de discriminação contra pessoas com deficiência, na Guatemala.

Essas convenções desencadearam resoluções e diretrizes que indicaram a eliminação de barreiras arquitetônicas (Resolução $\mathrm{n}^{\circ} 2$ do Conselho Nacional de Educação - CNE, 11/9/2001), como também a descrição da habilitação necessária para que os professores possam ensinar a crianças com deficiência. Entre outras está a Resolução $n^{\circ}$ 1 do Conselho Nacional de Educação/Conselho Pleno (CNE/CP), 18/2/2002, ao definir que as universidades devem prever em sua organização curricular a formação dos professores voltada para o acolhimento e trato da diversidade (Artigo $2^{\circ}$ ), contemplando conhecimentos sobre as especificidades dos alunos com necessidades educacionais diferenciadas (Artigo $6^{\circ}$, $\S 3^{\circ} \mathrm{II}$ ), e em seu Artigo $3^{\circ}$, II, letra d, apresentando uma coerência entre a formação oferecida e a prática esperada do professor, tendo em vista:

d) a avaliação como parte integrante do processo de formação, que possibilita o diagnóstico de lacunas e a aferição dos resultados alcançados, consideradas as competências a serem constituídas e a identificação das mudanças de percurso eventualmente necessárias. (Resolução ${ }^{0} 1$ do CNE/CP, 18/2/2002, Artigo 3으. II, letra d)

Entre as leis que regulamentam a acessibilidade, encontramos a Lei ${ }^{\circ} 10.436$ de 24/4/2002, ao reconhecer a Língua Brasileira de Sinais (LIBRAS) como um meio legal de comunicação e expressão, sem substituição da modalidade escrita da língua portuguesa, e, ainda, a Lei $\mathrm{n}^{\circ} 5.026 / 05$ de 22/12/2005, que dispõe sobre a inclusão de LIBRAS como disciplina curricular no curso de formação de professores para o magistério em nível médio e superior e nos cursos de Fonoaudiologia.

Mais recentemente, a extinta Secretaria de Educação Especial (SEESP), por meio da Política Nacional de Educação Especial na Perspectiva da Educação Inclusiva, MEC/20098, reforçou o papel da educação especial como complementar e suplementar e, portanto, não substitutiva da educação regular. Por não indicar o credenciamento de serviços públicos ou privados e o estabelecimento de convênios ou parceiras, o documento recebeu um grande número de críticas do meio acadêmico e de associações comunitárias e filantrópicas que entenderam a indicação para o fechamento destas instituições. Esse documento, mesmo não regulamentado, vem sendo utilizado e prevê o atendimento especializado a ser realizado em salas de recursos nas próprias escolas e em centros especializados de referência. Para que seja possível, o Decreto $n^{\circ} 6571$ de 17 de setembro de 2008 dispõe sobre o atendimento educacional especializado, ampliando sua oferta e garantindo o apoio técnico e financeiro aos sistemas públicos de ensino dos estados, municípios e do Distrito Federal que prestarem esse atendimento aos alunos com deficiência. 
Art. $8^{\text {o: }}$ Os alunos com deficiência serão contabilizados duplamente, quando matriculados em classes comuns do ensino regular e no atendimento educacional especializado, este podendo ser ofertado pelo sistema público de ensino, bem como pelas entidades mencionadas no Art. 14 do Decreto 6.253/2007, que trata das instituições comunitárias, confessionais ou filantrópicas sem fins lucrativos. (MEC/ CNE. Parecer 13/2009) ${ }^{1}$

Apesar de garantir que as escolas receberão esse incentivo, os textos legais continuam imprecisos, o que têm causado sérios problemas de exclusão, na medida em que não se consegue diferenciar entre a educação especial tradicional da forma de praticá-la como formação complementar específica: o atendimento educacional especializado (MANTOAN, 2008, p. 30).

As classes especiais e as escolas especiais tradicionais são excludentes, pois segregam os alunos. A escola comum não pode ser substituída pelo ensino especial e essa modalidade de ensino deveria complementar a formação do aluno, como está colocado na Política Nacional da Educação Especial na perspectiva da Educação Inclusiva:

Na perspectiva da educação inclusiva, a educação especial passa a integrar a proposta pedagógica da escola regular, promovendo o atendimento às necessidades educacionais especiais de alunos com deficiência, transtornos globais de desenvolvimento e altas habilidades/superdotação. Nestes casos e outros, que implicam em transtornos funcionais específicos, a educação especial atua de forma articulada

\footnotetext{
${ }^{1}$ Cabe comentar que no período em que a pesquisa foi realizada o Decreto 6571/08 estava em vigor. Porém, em 17/11/2011, o mesmo foi revogado e publicado um novo decreto (7611/2011), que permite que as classes especiais de escolas regulares e as escolas especiais ou especializadas substituam a escolarização em classes comuns de escolas regulares.
}

com o ensino comum, orientando para o atendimento às necessidades educacionais especiais desses alunos. (MEC/SEESP, 2008)

Pode-se observar, também, que existem diferentes formas de designar o sujeito deficiente na legislação. Marquezan (2009, p. 133) esclarece que se por um lado isso demonstra a atualização vinculada ao discurso da ciência, por outro produz um efeito de dissimulação do processo de exclusão e esvazia o "lugar de significar que o sujeito deficiente pode ocupar”. Para o mesmo autor, ao sobrepor as designações de pessoa deficiente a partir de discursos médicos, psicológicos e/ ou pedagógicos, o espaço da constituição se torna um lugar em litígio.

Da mesma maneira, a palavra "preferencialmente”, presente nas leis que se referem às crianças com deficiências, produziu, segundo Marquezan (2009), um silenciamento entre as duas formas de interpretar o sentido da lei: a que defende o atendimento total na rede regular de ensino e a que defende o atendimento na rede regular de ensino e pela educação especial.

De acordo com o exposto até então, levantamos alguns questionamentos que orientaram a pesquisa: como a inclusão tem ocorrido em nossas escolas? Como os professores participam desse processo e como percebem o que ocorre na dinâmica da inclusão? Que concepções norteiam a prática docente com alunos deficientes?

\section{Procedimentos metodológicos}

Com uma abordagem metodológica de cunho etnográfico, procuramos conhecer o processo de inclusão de perto, por meio da observação em escolas, em salas de aula e recreios, entre outros espaços escolares. 
Tal investigação se deu de acordo com uma abordagem qualitativa. Lüdke (1986, p. 11) ensina que é cada vez maior o interesse no uso de metodologias qualitativas por pesquisadores da área de educação. Porém, como orienta a autora, devemos nos acautelar e procurar conhecer como se caracteriza uma pesquisa qualitativa, para manter o rigor científico nesse tipo de investigação.

Mais interessadas no processo do que no produto escolar, na procura de descrever densamente a realidade observada e analisando de forma indutiva os dados obtidos (ANDRÉ, 1995), mergulhamos em salas de aula de duas escolas na cidade de Petrópolis (RJ). As escolas foram escolhidas por serem conhecidas como "escolas inclusivas".

Durante quatro meses estivemos nas escolas duas vezes por semana, um dia em cada uma, e permanecemos nos locais observados por cerca de cinco horas, com o propósito de olhar, ouvir e escrever (CARDOSO DE OLIVEIRA, 1988). Munidas de cadernos de campo, registramos atitudes, gestos, movimentos, diálogos, brincadeiras, palavras e frases, tanto dos alunos quanto das professoras, e principalmente cenas em que havia interação entre os professores e os alunos e entre os alunos sem deficiência e alunos com deficiência.

Compondo a pesquisa qualitativa, foram entrevistadas sete professoras das escolas observadas, bem como duas diretoras e uma coordenadora. A partir de um roteiro semiestruturado que privilegiava dados pessoais, informações sobre a prática docente e questões sobre a inclusão escolar, buscamos concepções, crenças e percepções dos docentes e gestores no trabalho pedagógico com estudantes com deficiência. Foram entrevistadas também três professoras da rede pública, que lecionavam em escolas que não são consideradas inclusivas. O objetivo dessa fase do trabalho de campo foi ouvir informações a partir de diferentes lugares sobre o tema da inclusão nas escolas.

Apesar de nossa Constituição garantir o direito para todos estudarem "preferencialmente na rede regular de ensino", independentemente de suas diferenças, algumas escolas e professores não acreditam nesta realidade, como afirma Aline, uma das professoras entrevistadas: "Na escola que trabalho não ensinamos para crianças com deficiência."

Cabe registrar que para fins desta pesquisa, os nomes das professoras, diretoras e das crianças foram modificados, para preservar seu anonimato. As falas dos participantes estarão sempre apresentadas em itálico.

A primeira escola (que vamos designar por PB) é pública, está localizada em um bairro afastado do centro da cidade e possui 700 alunos divididos em dois turnos, sendo 36 alunos deficientes. Em cada um dos turnos também há uma sala de Classe Especial, com seis alunos no turno da tarde e seis no turno da manhã. As outras 24 crianças estão distribuídas pelas turmas regulares. A diretora explicou: "Nossa escola é uma escola que todos já conhecem como uma escola inclusiva. A Secretaria de Educação é que manda as crianças pra cá. As outras escolas rejeitam as crianças, nós não."

Quando estivemos pela primeira vez na escola, a diretora apresentou uma tabela, com a relação de crianças com deficiência que estão matriculadas. Na tabela, estão distribuídos em colunas: o nome dos "alunos"; o tipo de "deficiência"; se possuem "laudo" de algum profissional que diagnostique a deficiência; a "classificação", ou seja, se são encaminhados pelo MEC ou pelo próprio município; o "ano escolar" e o "turno" que frequentam. Perguntamos por que alguns alunos deficientes e não todos estão na classe especial e a diretora da Escola PB explicou: "Algumas crianças são encaminhadas pelo 
município e podem não possuir laudo identificando a deficiência. Outras são classificadas como vindo do MEC. A colocação nas turmas ocorre a partir do momento em que elas têm capacidade para ficar lá."

Entende-se que os alunos são qualificados a partir de um diagnóstico de deficiência, fornecido por um laudo ou por um encaminhamento feito pelo MEC.

Fomos conhecer a escola, acompanhadas por uma das coordenadoras, que ao entrar em cada sala sempre perguntava para a professora: "Aqui tem aluno incluído?"2 Passamos a descrever as primeiras observações nas escolas pesquisadas.

Ao entrar na sala do $2^{\circ}$ ano da professora Sílvia, observamos que há dois meninos e 14 meninas, incluindo Luiza, uma criança com deficiência. Segundo a classificação utilizada pela escola e feita pela Secretaria de Educação, ela é uma criança com "deficiência visual e hidrocefalia”. Luiza estava sentava em uma cadeira de rodas e à frente havia uma mesa adaptada com um laptop também adaptado para deficientes visuais. O computador possuía um programa DOSVOX, teclado em braile e fones de ouvido: cada letra ou palavra após ser teclada é seguida pelo som correspondente. Notamos que algumas crianças faziam o dever no livro didático de português, outras não tinham o livro e desenhavam em folhas soltas. Luiza escrevia no computador os nomes dos colegas. A professora disse em voz alta: "Ontem o computador não funcionou e a atividade precisa ser realizada." Essa atividade continuou até o início da aula de matemática. Algumas crianças começaram a folhear o livro didático de matemática para conhecê-lo e as

${ }^{2}$ Cabe comentar que a categoria aluno incluído apareceu durante toda a pesquisa de campo, nos levando a indagar se a questão da inclusão escolar de alunos com deficiência não estaria criando um novo tipo de aluno. que não tinham o livro sentaram com os colegas, e algumas continuavam a desenhar em folhas soltas. Luiza continuava a escrever o nome dos colegas e passou a escrever os nomes dos números de um até cinco.

A outra sala observada foi a de $1^{\circ}$ ano, com a professora Silma e 15 alunos: oito meninos e sete meninas. Entre eles estavam os "alunos incluídos": Pedro, classificado com TGD (autismo), que dormia com a cabeça apoiada na carteira, e Kleber, que, segundo ela, "não tem diagnóstico ainda, porque a família não se interessa em buscar". A professora informou: "Eu trouxe o colchão para ele deitar, mas a mãe de Pedro falou que durante as férias ele dormia após o almoço, $e$ se ele deitar no colchão vai se acostumar e não vai querer ficar acordado." Silma explicou que teria mais dois alunos com deficiência. Ela tentou acordar Pedro, mas ele nem se mexia. Ficamos mais algum tempo na sala de aula e a professora avisou que as crianças iriam sair para brincar.

Ao retornar alguns dias depois na mesma sala de aula, encontramos os estudantes lanchando, com sucos e biscoitos sobre as carteiras. Pedro estava dormindo novamente, agora deitado em um colchonete na lateral da sala, embaixo da janela. A professora disse: "Ele está ficando mais acordado agora." Ela foi em direção a ele, acordou-o e Pedro levantou-se, ficando parado no meio da sala. Silma colocou-o então sentado na carteira e as atividades escolares continuaram.

Conhecemos também a Classe Especial, com seis alunos: Luis, 6 anos; Alberto, 12 anos; Renato e Natalia, com 13 anos (classificados como portadores de deficiência mental); ${ }^{3}$ Marina, 16 anos, com síndrome

\footnotetext{
${ }^{3}$ Deficiência mental: atualmente denominada por deficiência intelectual, significa desempenho intelectual significativamente inferior à média, com manifestação antes dos 18 anos e limitações associadas a duas ou mais áreas de habilidades adaptativas, tais como:
} 
de Down; e Leandro, que entrou na escola naquele mesmo dia, encaminhado pela Secretaria de Educação Especial, com um diagnóstico de síndrome de Dravet ${ }^{4}$ e deficiência mental. A professora informou que é pós-graduada em Educação Especial. Segundo ela, “as crianças estão 'quase' indo para as salas regulares, pois a educação especial é somente uma 'ponte' para elas irem para as salas com todos".

A coordenadora da Escola PB não soube explicar por que alguns alunos ainda estão na Classe Especial: "São duas turmas com seis alunos em cada uma e o tempo de permanência nas turmas é em média de oito a doze anos."

Tudo indica que os critérios previamente definidos, que permitem ao aluno com deficiência ingressar no ensino regular e ser matriculado em uma ou outra série ou na Classe Especial, não estão completamente claros. A diretora explicou: "É o departamento de educação que diz para onde vai cada criança enviada por eles, mas as diretoras também podem interferir." A coordenadora também ponderou: "O Leandro, aluno novo, não poderia estar na sala regular, mas também outros não podem. Têm alguns parâmetros que não estão bem definidos pra gente."

Portanto a entrada e permanência de alunos na Classe Especial são justificadas para algumas crianças, mas para outras não.

A Escola PR, como iremos chamá-la, é particular e localiza-se no centro histórico da cidade. Possui 300 alunos - seis com

comunicação, cuidado pessoal, habilidades sociais, utilização da comunidade, saúde e segurança, habilidades acadêmicas, lazer e trabalho (TECKLIN, 2002).

${ }^{4}$ Síndrome de Dravet corresponde a uma encefalopatia epiléptica e cursa com deterioração progressiva cognitiva/motora/sensorial, decorrente da atividade epiléptica persistente e resistente ao tratamento farmacológico (BIBLIOTECA DIGITAL UNICAMP). deficiência. Essas seis crianças estão distribuídas pelas classes, conforme suas idades, menos Carlos, que tem 13 anos e está na sala do Jardim II. A diretora informou que por ser uma criança com múltiplas deficiências, com severa limitação em responder ao esperado pelo contexto de aprendizagem e interação social, e por já estar na escola há 10 anos, a mãe participou da escolha da turma do menino, optando pela sala com crianças menores.

Observamos uma sala de $1^{\circ}$ ano com 16 crianças: nove meninos e sete meninas, sendo três deficientes: uma menina com síndrome de Down, Giovana; um menino com transtorno desafiador de oposição, ${ }^{5}$ Bruno; e Juliano, um menino em avaliação médica. ${ }^{6}$ Segundo a professora, "ele tem uma incoordenação motora: ele anda, não fala, mas compreende tudo o que falamos com ele". Segundo ela, "Juliano começou a andar com 3 anos e então parou de falar".

A turma tinha uma professora e uma estagiária. A observação estendeu-se durante a tarde e pudemos perceber que apesar dos alunos interagirem constantemente, Juliano procurava afastar-se o tempo todo. Percebemos que o menino se deslocava lentamente para longe do grupo, tanto quando estavam sentados no chão, arrastando-se sentado, quanto quando estavam nas carteiras: ele levantava-se e ia em direção à porta. A professora o chamava e direcionava-o; a estagiária, diferentemente, o pegava pelo braço e colocava-o em seu lugar. Quando percebia que ninguém olhava, Juliano começava novamente a se afastar.

\footnotetext{
5 O transtorno desafiador de oposição, segundo Serra-Pinheiro (2008), corresponde a um transtorno comportamental infantil caracterizado por um padrão global de desobediência, desafio e comportamento hostil.

${ }^{6}$ As avaliações e relatórios devem ser entregues no ato de matrícula das crianças. Esta criança está em avaliação.
} 
As crianças estavam escolhendo e cortando figuras, para colá-las nos cadernos e escrever seus nomes. Bruno não aceitava entrar na sala e a diretora da escola procurava envolvê-lo, convidando-o a participar sem confrontá-lo para que não se rebelasse, como, por exemplo, andando pela escola. Cabe mencionar que é a diretora que faz a adaptação de todos os alunos, com ou sem deficiência.

Passado algum tempo, os estudantes entraram na sala, sentaram no chão, e começaram a folhear revistas. A diretora tentava repetir a atividade realizada na sala, estimulando Bruno para que escolhesse figuras. Juliano desceu de sua carteira e, deslocando-se, sentado no chão, aproximou-se e ficou perto de Bruno. Giovana levantou-se também, aproximou-se de Juliano e sentou-se no chão. Após o término da aula a diretora comentou: "As crianças deficientes se aproximam sempre, é como se existisse uma cola entre elas." Essa aproximação nos fez pensar em uma questão que nos acompanhou em toda a observação de campo: será que se aproximam porque querem ficar junto a "seus iguais" (GOFFMAN, 1975) ou se aproximaram da diretora da escola porque ela trouxe algo interessante para a sala?

\section{Categorias de análise}

Após a leitura detalhada dos cadernos de campo e das entrevistas, sempre com os olhos voltados para os alunos com deficiências, com os ouvidos dirigidos para os professores, mas sem perder de vista os outros alunos, tampouco a interação entre todos os atores, participantes da construção da inclusão escolar, foram elaboradas duas categorias de análise, divididas em três subcategorias.
Segundo Minayo (2007), as categorias são rubricas ou classes que reúnem um grupo de elementos gerados a partir da pesquisa de campo, sob um título genérico. Para a autora, a categorização tanto pode ser construída previamente quanto pode surgir a partir da análise do material da pesquisa.

Dessa forma, realizamos categorizações que dessem conta das respostas das questões orientadoras da pesquisa, no sentido de descrever, conhecer e avaliar modos de agir de professores cujas salas de aula têm alunos considerados "incluídos", ou seja, como a inclusão de alunos deficientes tem ocorrido em nossas escolas? Como os professores participam desse processo e como percebem o que ocorre na dinâmica da inclusão?

$\mathbf{1}^{\text {a }}$ Categoria - O aluno com deficiência na sala de aula:

- Os alunos deficientes e a professora;

- Os alunos deficientes e a comunidade escolar;

- Interação entre os alunos.

$2^{\text {a }}$ Categoria - As professoras e suas percepções:

- Sobre inclusão e integração;

- Sobre as dificuldades em ensinar crianças deficientes;

- Sobre o que é preciso para ensinar crianças deficientes.

\section{$1^{a}$ Categoria: Os alunos com deficiência na sala de aula}

A presença de alunos com deficiência nas escolas é crescente e a maioria das professoras entrevistadas já teve este tipo de aluno em suas salas de aula. Mais do que um "modismo", "politicamente correta” e também "feita com naturalidade", como descrito por algumas das professoras entrevistadas, a inclusão de crianças deficientes está prescrita na lei e é um direito. 
Porém, mesmo nas escolas que já vêm desenvolvendo essa prática há mais tempo, esse processo não está programado ou entendido, pois é complexo e multifacetário, e envolve muitas dúvidas em sua execução. Mantoan (2006, p. 39) explica:

Ao contrário do que alguns pensam, não há inclusão se a inserção de um aluno é condicionada à matrícula em uma escola ou Classe Especial. A inclusão deriva de sistemas educativos que não são recortados nas modalidades regular e especial, pois ambas se destinam a receber alunos aos quais impomos uma identidade, uma capacidade de aprender, de acordo com suas características pessoais.

Isso significa que a presença de alunos com deficiência na sala de aula não quer dizer que estejam incluídos tanto no processo de aprendizagem como também no de socialização. Algumas professoras manifestaram indignação com um processo que não compreendem:

Eu acho inclusão uma farsa. Eu acho que na verdade eles não estão incluídos. Outro dia teve uma reunião pedagógica e a gente tava falando sobre isso, e até mudamos o termo, eles estão inseridos. Vê, na minha turma eu tenho três, que na verdade fazem as mesmas coisas que os outros. Você não tem como dar atenção individual a cada um, dependendo do número de alunos, porque cada deficiente tem uma deficiência diferente. Até eu atender, compreender o que cada deficiente precisa, acabou a aula e não fico pronta nunca, porque cada caso é um caso. Na verdade nós não estamos preparados pra trabalhar com essas deficiências. (Professora da escola PB).

Concordamos com Mantoan (2006, p. 9) quando diz que "para terem direito à escola, não são os alunos que devem mudar, mas a própria escola!”.
Portanto, com um olhar basicamente inclusivista, ou seja, numa perspectiva em que as diferenças precisam ser valorizadas e não apagadas, ou niveladas e esquecidas, e diante da complexidade de fatores que compõem a escola, pontuamos alguns aspectos que poderão ajudar a entender a presença de alunos com deficiências nas salas de aula de escolas comuns.

\section{Os alunos deficientes e a professora}

Para orientar o trabalho de pesquisa em sala de aula, na observação da relação entre os alunos deficientes e a professora, escolhemos como modelo de observação, "uma espécie de topologia social de sala de aula: o modelo centro-periferia”. Segundo Sá Earp (2006, p. 255), “Como poderia ser descrita a estrutura 'centro e periferia'? Tudo se passa como se o professor dirigisse o ensino a alguns alunos e não a todos os alunos da classe. Tais alunos seriam o 'centro'. Os outros seriam a 'periferia'”.

Para a autora, o modelo "centro-periferia” é descrito pelos modos de agir dos professores na interação com os alunos na classe. As maneiras como o professor faz perguntas aos alunos, os modos de responder às questões dos alunos, as formas de “corrigir" respostas, os modos de chamar os estudantes, tudo isto varia segundo a "posição" em que o professor coloca os alunos: no “centro" ou na "periferia”. Mais ou menos conscientemente, os professores têm padrões de interação diversos com os estudantes na mesma aula.

Foi interessante constatar que os alunos com deficiência eram o "centro" nas salas de aulas das escolas públicas, uma vez que as professoras permaneciam ao seu lado, segurando em sua mão, auxiliando-as 
a escrever, ditando individualmente e, por vezes, fazendo a atividade por eles. Quando faziam perguntas eram rapidamente respondidos ou corrigidos; o ritmo da aula obedecia à velocidade do aluno com deficiência. Usando a terminologia proposta por Sá Earp, os outros alunos são a "periferia" da aula.

Durante a entrevista, uma professora da escola PB descreve um momento vivido em sala de aula com um aluno deficiente, que retrata este modelo.

Fizemos um trabalho na sala com a cor vermelha. Depois de um tempão, Cláudio demorou um tempão pra colorir o quadrado, porque ele não presta a atenção, ele não entende nada. Eu perguntei a ele: "Que cor é essa?” Ele respondeu: 'Azul.' Perguntei de novo e ele respondeu: 'Azul.' Fiquei 40 minutos com ele. Só pra ele. As crianças chegavam na mesa pra perguntar e eu não dava atenção. Ficava só com ele. (Rafaela, professora da Escola PB).

Nas salas de aula em que havia a presença de estagiárias também foi encontrado o princípio “centro-periferia”, porém com uma variação: a estagiária permanecia todo o tempo com a criança com deficiência, e os outros alunos, acompanhados pela professora, eram divididos em "centro-periferia", como na descrição a seguir:

Observamos que os cadernos foram distribuídos para que as crianças copiassem o que está sendo escrito no quadro: 'Nome da escola. Petrópolis, 15 de março de 2011. Ditado.' Paula, a professora explicava: 'Copiem do quadro e após terminarem podem sair para o lanche.’ As crianças começaram a escrever. Notamos que Tomás, um aluno sem deficiência, olhava para o lado, para cima e para a janela. Abria e fechava o estojo, pegava um lápis, devolvia-o e pegava outro, pegava a borracha e começava a escrever. A ponta do lápis quebrou e ele levantou-se para apontá-lo na lata de lixo. Voltou para a carteira e recomeçou a mexer no estojo, guardando o lápis e pegando outro. As crianças iam terminando e saindo da sala para o lanche. Lilian, a estagiária, sentada entre Juliano e Giovana, auxiliava-os na realização da tarefa. A professora passava pelas carteiras olhando a atividade feita pelos alunos, passava por Tomás e não falava nada. Tomás arrumou suas coisas e foi lanchar com as outras crianças que já haviam terminado a cópia. (Escola PR).

\section{A relação entre os alunos com deficiência e a comunidade escolar}

Apesar de encontrarmos um número maior de alunos com deficiências nas escolas atualmente, esta presença é carregada de desconhecimento e dúvidas acerca das características que as crianças apresentam. Trazendo a marca do "estigma" (GOFFMAN, 1975), esses alunos podem ser vistos como diferentes dos chamados normais, como pode ser observado na seguinte descrição:

Começou o intervalo. As crianças começaram a pegar seus lanches e Silma, a professora, segurando Pedro pela mão, foi em direção à Secretaria. Chegando lá, ela disse para a secretária entregar o microfone para ele. Cristina pegou o microfone, colocou-o na mão de Pedro e falou: 'Ele adora!' Bianca, que também trabalha na Secretaria, estimulava-o: 'Canta Pedro! Canta!' Pedro permanecia em pé, segurando o microfone com as duas mãos, a cabeça inclinada e um ar de sorriso nos lábios, acompanhando com os olhos todos os que passavam. A professora de matemática passou por ele, olhou e disse: 'Eles são uma gracinha mesmo!' Pedro permaneceu assim até chegar Márcia, que retirou o microfone de suas mãos e dizendo 'Vamos fazer xixi.' 
Saíram da sala. Cristina dirigiu-se a nós e falou novamente: 'Ele adora, não é?' (Escola PB).

Cabe informar que a prática de cantar ao microfone na secretaria da escola somente é permitida e estimulada para os alunos com deficiência, tanto os da Classe Especial como os de classes regulares. Com um sentido duvidoso, esse tipo de “inclusão” está preso aos costumes do século XV, quando a pessoa deficiente, vista como um ser bizarro, era exposta e aplaudida como os bobos da corte.

\section{A interação entre os alunos}

A terceira subcategoria corresponde ao relacionamento entre as crianças dentro da escola e da sala de aula, peça fundamental para a aprendizagem. Para Pacheco (2007, p. 148), “as escolas inclusivas devem considerar a aprendizagem como um processo social em que a interação social tem um papel central para facilitar a aprendizagem”.

Nas observações realizadas, percebeu-se que a maioria das interações sociais ocorreu dentro das salas de aula, em decorrência de que os ambientes são pouco sensíveis às características diferenciadas de deslocamento dessas crianças.

Foi observado que as atitudes espontâneas das crianças em se ajudarem favoreceram o desencadeamento de comportamentos solidários mútuos. Descrevemos uma situação observada que pode esclarecer:

A aula de inglês irá começar. Juliano continuava inquieto e ia sempre em direção à porta. A professora procurava dar limites, orientações para que ele retornasse, sentasse melhor, sem pegar em sua mão, sem pegar em seu corpo e sim o estimulando para que fizesse sozinho. Ele levantava e queria sair da sala. Ficava de frente para a porta tentando abri-la. Quando conseguia abrir a porta, saía e ficava de frente para a parede, do lado de fora da sala. Novamente a professora ia atrás dele e colocava-o novamente sentado em sua cadeira, mas bastava que virasse de costas para que ele começasse a empurrar a cadeira, olhando para fora, demonstrando vontade de sair da sala. Com a repetição, ao perceber que a professora estava olhando para ele, Juliano parava de se movimentar até que ela olhasse para outro lado e ele tentava novamente. Ela retornou, pegou-o novamente, olhou e disse em voz alta: 'Além de tudo falta limite!' Um aluno sentado na carteira à frente de Juliano começou a ajudar, posicionando-o e colocando suas pernas para baixo, falando para que ele ficasse quieto. Juliano foi acalmando até que o colega sentou-se ao lado dele. Juliano ficou quieto. Paula olhou e não falou nada. (Escola PR).

\section{$2^{\text {a }}$ Categoria: As professoras e suas percepções}

Esta categoria emerge da participação das professoras, de como percebem e realizam sua prática com a presença de crianças com deficiências nas salas de aula. Foi identificada uma incompatibilidade entre a fala dos diretores, coordenadores e dos professores das escolas observadas, conhecidas e declaradas como escolas que incluem crianças com deficiência, indicando que a inclusão não é um projeto construído na comunidade escolar. As falas de algumas professoras nos revelam:

Em todas as reuniões a gente fala o seguinte: que a nossa escola é referência de inclusão. Já me intitulei e já me dei o título, quer dizer, dei à escola. Agora eu gostaria de destacar muito a equipe, porque se eu não tivesse uma equipe também que 
abraçasse essa causa, a gente não toparia nada, eu sozinha, lógico, não teria como resolver nada. (Diretora, Escola PB).

Inclusão é uma situação difícil, possível desde que tenha mais preparo. Não é preparo humano não, é preparo mínimo: acessibilidade. Porque você acaba se virando com tudo! Vou te dar um exemplo: aqui na escola a gente não tem fraldário, a gente não tem uma rampa direito, a gente não tem um banheiro próprio, e a coisa vai funcionando de acordo com o que tem. Isso é um fator. Acho que o governo tem que assumir isso, por ser escola pública. Tem que assumir esse papel. Nós nunca vamos estar preparadas pro diferente; a gente só consegue aprender sobre o diferente, sobre o que é possível, sobre o que a criança desenvolve ou não desenvolve experimentando a situação. (Professora, Escola PB).

Mantoan (2006, p. 44) traz importante colaboração ao informar que "Não se pode encaixar um projeto novo, como é o caso da inclusão, em uma velha matriz de concepção escolar”.

\section{Sobre inclusão e integração}

Nas observações feitas nas salas de aula, foi percebido que em alguns momentos vigorava o modelo de integração, em que não são feitas adaptações para os alunos deficientes nas atividades propostas pelos professores. Já em outros, foram visualizadas dinâmicas em que são consideradas as diferenças entre as crianças com a aplicação de práticas diferenciadas, tendo um objetivo comum a todos. Exemplificamos nas descrições a seguir:

Entramos na sala e as crianças estavam copiando do quadro algumas palavras, escritas pela professora, em ordem alfabética, com o título: 'Coisas que a mamãe usa.' Pedro estava deitado no colchão, dormindo. A professora estava em sua mesa fazendo contas em sua calculadora. Eram as despesas com o presente do Dia das Mães que estava confeccionando: um pano de prato, verdeclaro, com um desenho feito pelas crianças com canetinha de tecido. As crianças já estavam acabando o dever e começaram a colocar o caderno em cima da mesa de Silma, que continuava a fazer contas. Pedro acordou e então Silma levantou-se, foi buscá-lo e sentou-o em sua carteira.

Kleber, que estava sentado na primeira fileira, levantou-se, foi até a mesa da professora e perguntou: 'Com c é sandália?' A professora respondeu: 'Sandália não é com c, é com s. Com c é o que?' Kleber permaneceu em silêncio. 'Celular. Celular é com c', falou Silma. Kleber continuou quieto, em pé, frente a ela. A professora começou a falar a palavra celular, repetidas vezes, sílaba por sílaba, contando nos dedos: 'Ce-lu-lar, Ce-lu-lar, Ce-lu-lar. Quantas sílabas têm celular?’ Silma continuava repetindo a palavra, falando alto e pausadamente, sempre repetindo: 'Ce-lu-lar. Quantas sílabas tem?’ Até que Kleber respondeu: 'Três.' A professora falou então: 'Muito bem, então volta pro seu lugar e vai escrever celular.’ Kleber voltou lentamente, repetindo a palavra celular, contando nos dedos o número de sílabas e repetindo: 'Ce-lu-lar, três, ce-lu-lar, três, ce-lu-lar, três.' Ao chegar a sua carteira olhou-nos e falou: 'Tia, como é que se escreve celular?' Silma falou em voz alta: 'Kleber, fique quieto e copie do quadro.' Pedro continuava sentado em sua carteira, balançando a cabeça para os lados, e ninguém falava com ele. O sinal tocou e as crianças foram para o recreio. (Escola PB).

Na Escola PR, as carteiras estavam posicionadas em $U$, o que facilitava para Paula, a professora, olhar o que as crianças faziam. A atividade desenvolvida era 
uma escrita espontânea. As crianças inicialmente escreveram o cabeçalho e em seguida escolheram em revistas algumas figuras para escreverem o nome de cada uma no caderno. Juliano e Giovana eram ajudados por Lilian, a estagiária, que estava sentada entre eles e estimulando-os a escolher as figuras. Lilian também dispôs as letras para que ele as escolhessem e formassem as palavras. As letras seriam coladas ao lado das figuras escolhidas. Giovana era estimulada a cortar as figuras e a escrever seus nomes usando um lápis com um engrossador, para facilitar seu uso. Paula pediu para aqueles que já haviam terminado a atividade que formassem uma rodinha sentados. Lilian foi ajudar Tomás e Andrezza, que estavam atrasados.

Pode-se perceber também que para alguns professores a Classe Especial é vista como uma alternativa para os alunos deficientes, mesmo nestas escolas que são consideradas inclusivistas, ou seja, praticam a inclusão entre seus alunos. Segundo uma coordenadora da Escola PB:

A gente sabe que o próprio MEC não reconhece a Classe Especial. Não existe mais. Quando o MEC veio a Petrópolis no ano passado ele reconheceu o município como polo de referência para a inclusão e eles questionaram muito: 'Aqui nessa escola tem Classe Especial?’ Mas entenderam assim, a equipe explicou: 'a Classe Especial é como uma passagem.’

As professoras justificam a Classe Especial como sendo "uma passagem" ou "uma ponte" que prepara os alunos deficientes para a entrada na sala regular, condição necessária para alguns alunos, não todos.

A coordenadora da Escola PB não sabe explicar por que alguns alunos estão na Classe Especial por 10 e até 12 anos. A entrada de uma criança deficiente na escola também não é clara, como a diretora explicou:
É o departamento de educação que diz para onde vai cada criança enviada por eles, mas as diretoras também podem interferir. O Leandro, o aluno novo, não poderia estar na sala regular, mas também os outros não podem. Tem alguns parâmetros que não estão bem definidos pra gente.

\section{Sobre as dificuldades em ensinar crianças com deficiência}

Foi percebido nas entrevistas realizadas que as dificuldades descritas pelas professoras eram transferidas e confundidas com as "deficiências" que os alunos apresentavam: "A minha dificuldade depende da especialidade, da deficiência que o aluno tem" (Professora, Escola PR); "Eles não dão retorno. É o principal. É saber se eles estão me compreendendo ou não" (Professora, Escola PB).

Para Diniz (2009), há duas maneiras de entendermos a deficiência: a primeira como uma manifestação da diversidade humana; um corpo com limitações, tanto de caráter físico, intelectual ou sensorial, em um ambiente com barreiras sociais que ignoram os impedimentos corporais, levará à experiência de desigualdade. A outra maneira de ver a deficiência é como uma desvantagem, e deve ser feito de tudo para garantir a todas as essas pessoas "um padrão de funcionamento típico à espécie”. Dessa maneira, luta-se e recusam-se as deficiências, consideradas “indesejáveis" e não mais uma das representações da diversidade humana (DINIZ, 2009).

Dessa maneira, a concepção de que um corpo com essas características deve se submeter à metamorfose da normalidade, naturalidade ou igualdade, por meio das ações curativas da medicina, da reabilitação, da psicologia ou da educação e o deslocar da dificuldade da professora para a criança, são 
algumas das formas de opressão e de fomentar a desigualdade. A busca da normalização, da igualdade faz com que as diferenças sejam recusadas e, como afirma Monteiro (1998, p. 57), “não há necessidade de nivelar aquilo que nos contrasta, o que precisamos mesmo é educar o olhar para que possamos aprender com o diferente”.

As respostas de outras professoras levam a pensar que existem possibilidades:

Acho que, a princípio, a dificuldade é saber como você vai trabalhar. Depois tem muita tentativa. Igual a uma criança qualquer, você vai ensinar um número, ela não aprende e você tem que inventar outro jeito de trabalhar o número com ela. É a mesma coisa que trabalhar criança deficiente: você vai ter dificuldade, mas você vai ter que descobrir um jeito pra chegar naquela criança. Tem criança que se esquiva, e você tem que saber um jeito e cada criança é uma. A gente aqui também tem a psicóloga e a fonoaudióloga que ensinam e ajudam a gente, dando sugestões. (Professora Gilda, Escola PR).

\section{Sobre o que é preciso para ensinar crianças deficientes}

Por fim, um dos argumentos mais frequentes dos professores, frente à inclusão, é o de não estar preparados ou até de não ter sido habilitados para esse tipo diferenciado de trabalho educacional. Destarte, ao procurar conhecer sobre as necessidades das professoras, foi constatado que em sua maioria elas escalonaram como mais importante atributos afetivos, como "carinho", "amor" e "afeição", e alguns atributos pessoais, como “dedicação”, "paciência” e “dom”.

O dom é o principal, querer estar com a criança. Eu não tenho o dom pra trabalhar com criança especial e sou obrigada a trabalhar porque ela tem que estar incluída. (Professora, Escola PB).

Posso falar de coração? É de coração mesmo... É boa vontade, é você se afeiçoar, porque você acaba gostando muito porque você quer bem. Não adianta colocar as crianças em qualquer turma, se a professora não aceita... Uma boa aceitação... (Professora, Escola PB).

Interessante notar que a maior parte das professoras não considera que é a capacitação profissional que vai permitir ou facilitar o ensino a alunos com deficiências. Por outro lado também sabemos que não há capacitação única que responda às necessidades das professoras. Foi observado também que o desconhecimento sobre as necessidades dos alunos deficientes e suas potencialidades coloca as professoras com dificuldades em escolher, criar alternativas e entender em que situações elas poderiam agir com resultados mais eficientes e menos desgastantes. Muitas vezes as professoras se confundiram com terapeutas, como na situação descrita a seguir:

Na escola PB o sinal tocou para o recreio. Silvia quer que Luiza conduza sozinha sua cadeira de rodas, dando orientações como: 'Esquerda, direita, esquerda, mais pra esquerda, reto, vai reto, chegou na porta, agora tem uma rampa... cuidado... continua, pronto chegou no corredor." ${ }^{7} \mathrm{~A}$ professora falou alto no corredor: 'Quem vem pegar a Luiza?’ (Escola PB)

\footnotetext{
${ }^{7}$ Cabe notar que uma criança deficiente visual, dependente de cadeira de rodas, não poderá mover a cadeira sozinha porque não tem como avaliar o espaço que a cadeira irá percorrer: ou move a cadeira impulsionando as rodas com as mãos, ou explora o espaço com o uso da bengala. Por isso, ela depende de outra pessoa para se deslocar.
} 


\section{Considerações finais}

Com a perspectiva de que a inclusão de crianças com deficiência em escolas comuns possa equivaler à ampliação de suas habilidades a partir de suas diferenças e ao direito de vivenciar o que qualquer criança tem direito - a vida em sociedade -, percebe-se que muito ainda há de se fazer. Apesar de uma vasta legislação vigente no país, as pessoas deficientes ainda se encontram desamparadas na educação escolar.

A observação feita em escolas consideradas inclusivas permitiu que verificássemos que os três paradigmas - o segregacionista, o integracionista e o inclusivista - convivem no cotidiano escolar, assim como Anjos (2007) também descreveu. Realizando práticas de integração, com dinâmicas de inclusão e com a permanência de crianças em classes especiais por 10 a 12 anos, práticas de segregação convivem no dia a dia de escolas ditas inclusivas. Cumpre notar que escolas da rede privada não possuem classes especiais, porém são poucas aquelas que recebem crianças com deficiências entre seus alunos.

Com uma estrutura organizada no modelo "centro-periferia", de forma semelhante e ao mesmo tempo diferente, observamos que as professoras separam os alunos nas salas de aula e colocam os alunos deficientes no "centro" e os outros alunos na "periferia". Semelhante porque, com dificuldade em ensiná-los, permanecem ao lado dessas crianças, fazendo as atividades por elas, segurando em sua mão, sem criar alternativas para que possam aprender. Como a percepção das professoras é de que a dificuldade em aprender dos alunos está localizada em suas deficiências, elas justificam o não aprender ao declarar "é pela deficiência dela" ou "é por causa da dificuldade que ela tem". Diferente porque, nas salas de aula em que os alunos com deficiência são acompanhados por estagiárias, os outros alunos, sob a responsabilidade da professora, são separados em "centro" e "periferia", e a professora ensina mais àqueles selecionados para ocupar o centro.

Interessante notar que os paradigmas de inclusão e de integração são encontrados nas duas escolas e mesmo na escola privada, em que os alunos com deficiência ficavam sob a orientação da estagiária, não há modificação das práticas para atender à turma. Os alunos com deficiência tentam ou são ajudados a realizar o que todos fazem; em algumas situações, são criadas adaptações e em raros momentos as atividades são reorientadas para que todas as crianças possam participar. Algumas professoras relataram que realizam modificações nas práticas para atender a todos os alunos, mas os exemplos descritos são mais frequentes nas atividades festivas, como, por exemplo, as adaptações em presentes para o de Dia das Mães, ao trocarem as mensagens que seriam decoradas e verbalizadas por músicas que os alunos sabiam cantar - inclusive os alunos deficientes.

A maioria das professoras não sabe distinguir entre os dois paradigmas educacionais e parece desconhecer que não sabem. Percebemos que mesmo em situações em que as crianças estão realizando as atividades, atuando com suas potencialidades individuais, as professoras acreditavam que todos deveriam realizar a mesma atividade, numa clara percepção de que a crença na homogeneização ainda prevalece nas salas de aula.

Por não conhecerem a educação inclusiva e as políticas públicas para alunos com deficiência, para a maioria das professoras entrevistadas esta é uma proposta difícil de ser alcançada, tal qual uma quimera. Talvez por isso as professoras apontem atributos afetivos como mais importantes que capacitação profissional, para ensinar crianças com 
deficiência. Ao mesmo tempo que percebem que não estão "preparadas" para ensinar alunos com deficiências, as professoras não se sentem entusiasmadas a se instrumentalizar do conhecimento para reverter esta posição. Acresce-se a percepção da maioria das professoras de que a dificuldade em ensiná-los está localizada na "deficiência" que possuem. Sendo assim, pouco se faz para modificar e pouco se aprende nas escolas.

Porém, somente pelo conhecimento, pelas múltiplas abordagens e perspectivas é que se pode chegar à criatividade, a se imaginar-se e até a se colocar no lugar do outro, de alguém com características diferentes (RAGHAVA, 2011).

Buscamos, com esta pesquisa, descrever como a inclusão vem sendo vivida e percebida em escolas, a fim de ampliar as formas de pensar sobre as práticas pedagógicas a partir da mudança de concepção sobre a deficiência e no reconhecimento da diferença como um elemento favorecedor da aprendizagem.

\section{Referências}

ANJOS, Hildete Pereira dos; ANDRADE, Emmanuele Pereira de; PEREIRA, Miriam Rosa. A inclusão escolar do ponto de vista dos professores: o processo de constituição de um discurso. Revista Brasileira de Educação, Rio de Janeiro, v. 14, n. 40, jan./ abr. 2009.

ANDRÉ, Marli Eliza Dalmazo Afonso de. Etnografia da prática escolar. Campinas, SP: Papirus, 1995.

BIBLIOTECA DIGITAL DA UNICAMP. Disponível em: <www.bibliotecadigital. unicamp.br>. Acesso em: 15 jan. 2010.
CARDOSO DE OLIVEIRA, Roberto. O trabalho do antropólogo: olhar, ouvir, escrever. In: __. O trabalho do antropólogo. 2. ed. São Paulo: UNESP/ Paralelo 15, 1988. p. 17-35.

DINIZ, Débora. O que é deficiência. São Paulo: Brasiliense, 2007.

DINIZ, Débora; BARBOSA, Lívia; SANTOS, Wederson Rufino dos. Deficiência, direitos humanos e justiça. Revista Internacional de Direitos Humanos, Sur - Rede Universitária de Direitos Humanos, v. 6, n. 11, p. 65-78, dez. 2009. Disponível em: <http://www.surjournal.org/conteudos/ getArtigo11.php?artigo=11,artigo_03.htm>. Acesso em: 15 jan. 2011.

GOFFMAN, Erving. Estigma: notas sobre a manipulação da identidade deteriorada. Rio de Janeiro: Jorge Zahar, 1975.

LÜDKE, Menga; ANDRÉ, Marli E. D. A. Pesquisa em educação: abordagens qualitativas. São Paulo: EPU, 1986.

HOUAISS, Antonio. Dicionário Houaiss da Língua Portuguesa. Rio de Janeiro: Objetiva, 2001.

MANTOAN, Maria Teresa Eglér. Inclusão escolar: O que é? Por quê? Como fazer? São Paulo: Moderna, 2006.

Inclusão escolar: caminhos, descaminhos, desafios, perspectivas. In: MANTOAN, Maria Teresa Eglér (Org.). $O$ desafio das diferenças nas escolas. Petrópolis: Vozes, 2008.

MARQUEZAN, Reinoldo. O deficiente no discurso da legislação. Campinas: Papirus, 2009.

MEC. Política Nacional da Educação Especial na Perspectiva da Educação Inclusiva. Disponível em: <http://portal.mec. gov.br/arquivos/pdf/politicaeducespecial. pdf>. Acesso em: 12 maio 2010. 
MENDES, Enicéia Gonçalves. A radicalização do debate sobre inclusão escolar no Brasil. Revista Brasileira de Educação, Rio de Janeiro, v. 11, n. 33, p. 387-559, set./dez. 2006.

MINAYO, Cecília; DESLANDES, Suely; GOMES, Romeu (Orgs.). Pesquisa social: teoria, método e criatividade. Petrópolis: Vozes, 2007.

MONTEIRO, Pedro Paulo. Envelhecimento: rumo ao novo paradigma. Revista Kairós: gerontologia. Núcleo de Estudo e Pesquisa em Envelhecimento. Programa de Estudos Pós-Graduados em Gerontologia - PUC-SP, São Paulo, EDUC, ano 1, n. 1, 1998.

PACHECO, José et al. Caminhos para a inclusão: um guia para o aprimoramento da equipe escolar. Porto Alegre: Artmed, 2007.

RAGHAVA K. K. Shake up your story. Disponível em: <http://www.ted.com/talks/ raghava_kk_shake_up_your_story.html>. Acesso em: 3 abr. 2011.

SÁ EARP, Maria de Lourdes. A cultura da repetência nas escolas cariocas. 2006. Tese (Doutorado em Antropologia e Sociologia). Instituto de Filosofia e Ciências Sociais. UFRJ.

SERRA-PINHEIRO, Maria Antonia et al. Transtorno desafiador de oposição: uma revisão de correlatos neurobiológicos e ambientais, comorbidades, tratamento e prognóstico. Disponível em: <http://www. psiquiatrainfantil.com.br $>$. Acesso em: 3 mar. 2011.

TECKLIN, Jan Stephen. Fisioterapia pediátrica. 3. ed. Porto Alegre: Artmed, 2002.

Enviado em: 07/10/2011

Aceito em: 30/11/2011 